\title{
Wernicke-Korsakoff syndrome in Sydney hospitals after 6 years of thiamin enrichment of bread
}

\author{
S Rolland and AS Truswell* \\ Human Nutrition Unit, University of Sydney, New South Wales, 2006 Australia
}

Submitted 13 January 1998: Accepted 22 April 1998

\begin{abstract}
Objectives: To estimate the incidence of Wernicke's encephalopathy (WE) and Korsakoff's psychosis (KP) before and after the introduction of thiamin enrichment of bread in Australia.

Design and subjects: Inpatient records were examined in 17 major public general hospitals in greater Sydney for the 4 years 1993-96 (inclusive) with the International Classification of Diseases (ICD) 9 diagnoses 265.1 (WE), 291.1 and 294.0 (KP). Relevant clinical data were recorded on a specially designed form so that cases could be classified as confirmed or probable WE, confirmed or probable KP, confirmed or probable Wernicke-Korsakoff syndrome (WE + KP) or not WE or KP. The average number of cases of WE + KP was 38 acute (new) cases and 69 total (acute + chronic) cases per annum for all the hospitals combined.

Results: This study used the same methods as our earlier retrospective examination of Wernicke-Korsakoff cases in essentially the same hospitals for 1978-93. Records for 1993 were thus pulled twice and, while individual cases (using hospital index number) did not always coincide, the total numbers for 1993 were 69 and 70.

For the 5 years after 1991 the number of acute cases of WE and KP in Sydney hospitals was $61 \%$ of the number for the 5 years before $1991(P<0.01)$. There is, however, no continuing downward trend.

Conclusions: These results are consistent with a $40 \%$ reduction of the incidence of acute WE and KP since bread has been enriched with thiamin. The disease complex has, however, not been eliminated. To achieve this, further public health action would be needed, such as addition of thiamin to beer.
\end{abstract}

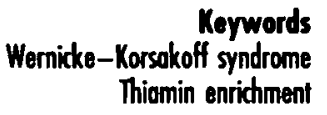

Australia has apparently had a higher incidence of Wernicke's encephalopathy (WE) and more people who require long-term care because of Korsakoff's psychosis (KP) than other comparable countries (e.g. USA, UK, Brazil, Germany, Norway, New Zealand) ${ }^{1-6}$.

Wernicke's encephalopathy is characterized by deranged mental function, usually a global confusionalapathetic state, with nystagmus and/or ophthalmoplegia and ataxia affecting stance or gait ${ }^{7}$. It usually occurs in people who have been drinking alcohol heavily and not eating but can occur after persistent vomiting ${ }^{8}$. When measured (before treatment), red cell transketolase activity and thiamine pyrophosphate (TPP) effect indicate thiamin deficiency', and the ophthalmoplegia and confusion respond to thiamin treatment. Korsakoff's amnesic psychosis is associated with $\mathrm{WE}^{7}$; typically it is recognized when the confusion clears in response to thiamin. KP sometimes responds slowly to thiamin but more often is persistent. WE is not easy to diagnose; to differentiate from other impairments of mental function in alcohol abusers, there is no rapid confirmatory special investigation. A patient with WE can die before being brought to hospital or in hospital if the condition is not quickly recognized, and it often goes on to the disabling amnesic syndrome, KP. Systematic postmortem studies in Perth found that only one-third of cases with neuropathological features of Wernicke-Korsakoff syndrome (WKS) had been diagnosed clinically as WE, KP or WKS during life ${ }^{10}$.

In the $1980 \mathrm{~s}$ Gold et al. ${ }^{11}$ estimated the incidence of WE across Australia to be about 500 cases per year. Other estimates have been similar ${ }^{12}$. This is clearly a disease complex that is more suitable for prevention than treatment ${ }^{13}$. In 1987 after years of discussion and repeated calls by psychiatrists ${ }^{14,15}$ and physicians ${ }^{16}$ the National Health and Medical Research Council (NHMRC) recommended the addition of thiamin to beer and flagon wine ${ }^{17}$. Nutrification of alcoholic beverages had no precedent anywhere in the world and was opposed by both the brewers and anti-alcohol lobby. After more discussions ${ }^{18}$ the NHMRC Nutrition Committee proposed that it would be better as a first measure to add thiamin to bread flour, a dietary staple, 
as is standard practice in most developed countries (though elsewhere this was done to restore B vitamins lost in refining whole wheat flour, not to prevent cerebral thiamin deficiency). Mandatory addition of thiamin to bread flour at the rate of $6.4 \mathrm{mg} \mathrm{kg}^{-1}$ of flour (as in the USA) was recommended by the NHMRC $^{19}$ and the Australian Food Standards Committee. This was implemented on 1 January 1991. Australian white breads now contain an average of $0.40 \mathrm{mg}$ thiamin per $100 \mathrm{~g}^{20}$ (compared with $0.13 \mathrm{mg}$ per $100 \mathrm{~g}$ before fortification).

No system for prospective monitoring of the effects of thiamin enrichment was set up by the Commonwealth government. So in $1994 \mathrm{Ma}$ and Truswell made a retrospective survey of the incidence of WKS in the 17 major public hospitals in the Sydney area for the years $1978-93$, i.e. 13 years before and 3 years after introduction of thiamin enrichment of bread ${ }^{21}$. We found that in the 3 years 1991-93 the numbers of cases of acute and chronic WKS, of acute WKS and of WE were somewhat lower than for any of the preceding 3 year periods. Acute WKS cases for 1992 and for 1993 were fewer than for any of the preceding 14 years. But numbers of cases had fluctuated from year to year and the regression slope for 1991-93 was not significantly different from that for 1978-90. At that stage we could only conclude that the hospital statistics were consistent with thiamin enrichment of bread having a partially protective effect against WKS but were not conclusive evidence. Longer follow-up in Sydney and other areas of Australia, and results from postmortem examinations would be required to establish whether the incidence of WKS had consistently and adequately declined $^{21}$.

\section{Methods}

Records were searched at 17 major public hospitals in the Sydney area: Bankstown/Lidcombe Hospital (BLH), Concord Repatriation General Hospital (CON), Fairfield District Hospital (FFH), Hornsby Kuring-gai Hospital (HOR), Liverpool Hospital (LIV), Manly District Hospital (MAN), Mona Vale Hospital (MVH), Nepean Hospital (NEP), Prince Henry Hospital (PHH), Prince of Wales Hospital (POW), Royal North Shore Hospital (RNS), Royal Prince Alfred Hospital (RPA), Ryde Hospital (RYD), St George Hospital (SGH), St Vincent's Hospital (SVH), Sydney Hospital (SYD) and Westmead Hospital (WMH). These were the same hospitals surveyed by Ma and Truswell in $1994^{17}$ except that BLH replaced Lidcombe Hospital, whose medical records were transferred in 1993 to BLH. Records for PHH and POW are combined.

The study was approved by the ethics committee of each hospital and strict privacy guidelines were followed. The records manager of each hospital was asked to pull medical records for four International Classification of Disease (ICD) $9 \operatorname{codes}^{22}$ for the 4 years 1993, 1994, 1995 and 1996:

- 265.1: other and unspecified manifestations of thiamin deficiency (the code for WE).

- 291.1: KP (alcoholic).

- 294.0: KP or syndrome (non-alcoholic).

- (265.0: beriberi was also checked).

Case medical numbers were found by computer. The individual records were then taken from the shelves manually. Each file was reviewed (by Rolland). A specially designed data form was filled in for each case. This contained clinical details to check if they would support the diagnosis of WE or KP. No names were written on our form - only the hospital identification number and our own research case number. Patients who had more than one admission to hospital for the years studied were counted only once. The criteria were similar to those used in our earlier study ${ }^{21}$. Small numbers of two other diagnoses were also recorded: 'thiamin deficiency' (with no mention of WE, KP or WKS) and nonalcoholic WKS.

The medical notes often contained a diagnosis of KP or WKS as part of the past history (not the reason for the present admission). If this was recorded as starting after 1 January 1993 the case was entered as 'chronic KP'; but if it was first recorded before 1993 the case was not counted; it should have been included in the earlier study from 1978 to $1993^{21}$. Misdiagnosed and miscoded cases were also excluded.

- WE confirmed was recorded if the patient had either (i) ophthalmoplegia and/or nystagmus and confusion which responded to thiamin, and/or

(ii) a red cell transketolase TPP effect above $40 \%$ and a background of alcohol abuse.

- WE probable was recorded if 'WE' was part of the official diagnosis but the above criteria were not found. - KP confirmed was recorded if 'KP' or 'alcoholinduced persisting amnestic disorder' was part of the official diagnosis and there was evidence of memory changes and a history of WE.

- KP probable was recorded if the official diagnosis was 'KP' or 'alcohol-induced persisting amnestic disorder' but documentation of memory changes or WE were not found.

- WKS confirmed was recorded for a case with confirmed WE + KP.

- WKS probable was recorded if 'WKS' was the official diagnosis but the criteria for clinical confirmation could not be found.

- If a patient died and the neuropathology report 
Table 1 Total numbers of WKS cases for the 17 hospitals combined

\begin{tabular}{lrrrrr}
\hline & 1993 & 1994 & 1995 & 1996 & Total \\
\hline WE confirmed & 12 & 3 & 16 & 6 & 37 \\
WE probable & 9 & 10 & 2 & 13 & 34 \\
KP confirmed & 0 & 1 & 0 & 0 & 1 \\
KP probable & 16 & 7 & 16 & 9 & 48 \\
WKS confirmed & 1 & 3 & 12 & 2 & 18 \\
WKS probable & 1 & 5 & 2 & 1 & 9 \\
'Thiamin deficiency' & 2 & 0 & 1 & 2 & 5 \\
Total acute & 41 & 29 & 49 & 33 & 152 \\
Chronic KP & 28 & 31 & 34 & 31 & 124 \\
Total all & 69 & 60 & 83 & 64 & 276 \\
\hline
\end{tabular}

diagnosed WE, KP or WKS, this case was placed in the relevant confirmed category.

\section{Results}

The cases from all 17 hospitals in the different diagnostic categories are shown in Table 1 . Acute cases were recorded as one of seven diagnostic categories. Below the total for seven different forms of acute WKS is the single line for chronic KP. Only one of the acute cases (WKS) was recorded as non-alcoholic $(0.65 \%)$. The average number of cases of WKS over the 4 years was 38 new (acute) cases per year and 69 total (acute + chronic) cases. Admission rates per 10,000 in the different hospitals (in descending order) were 3.1 at CON, 2.3 at RPA, 1.9 at WMH and MVH, 1.7 at MAN, 1.4 at FFH, 1.2 at POW and PHH, 1.1 at RYD and SYD, 1.0 at HOR and SGH, 0.9 at SVH, 0.8 at LIV, 0.7 at BLH, 0.5 at NEP and 0.2 at RNS.

The ratio of WE to KP (acute + chronic) was 1 to 3.7. The ratio of men to women was nearly 5 to 1 . The peak age was the 60-69 year decade. When the type of alcoholic beverage the patient had been drinking was recorded (in one-third of the cases) it was beer three times as often as any other type of drink. Blood sent for transketolase assay was only recorded for eight patients: the TPP effect was only abnormal in one case. (We could not tell whether the other bloods were taken before or after starting thiamin treatment.) Twenty patients died, not necessarily all from WE. Postmortem examinations were obtained on ten of these. Nine of these ten had the neuropathological features of WKS. Two of these nine had been diagnosed antemortem, not the other seven. Patients came from 126 different postcodes (all but one in NSW); the suburbs with the highest incidence were (in decreasing order): Rozelle, Parramatta, Liverpool, Bexley, Homebush, Leichhardt, Summer Hill, Ashfield, Narrabeen, Waterloo, Burwood, Coogee, Greenacre and Strathfield. The hospitals with the largest number of acute cases over the 17 years (in descending order) were WMH, RPA, CON, LIV, SGH and SVH. The hospitals with the largest number of chronic cases (in descending order) were CON, RPA, WMH, POW, SGH and MVH.

\section{Joining the present 1993-96 series to tbe previous 1978-93 series $^{21}$}

The present study collected WKS cases from 1993 which was also the last year for which files were examined in our previous study ${ }^{21}$. If location of records in hospitals was $100 \%$ efficient, the total number of cases, and the individual patients for 1993 should have been the same for each hospital. Data sheets from our 1978-93 survey $^{21}$ had been stored and individual patients were identifiable by their hospital number for comparison between the two studies. We found that many cases were indeed the same in both studies; some, however, appeared only in the present study, some only in the previous one. The biggest discrepancy was the discovery of extra cases in one of the large hospitals which had not been produced in the first study $^{21}$. Despite this finding the total number of cases for 1993 over all 17 hospitals for the two records searches was almost the same, 69 and 70 . Numbers in the two pulls of 1993 are in adjacent columns in Table 2, which shows the number of acute + chronic cases (WE + KP + WKS) for each hospital, the total numbers of acute cases and the total number of chronic cases for all hospitals combined for each year from 1978, past the 1993 join, up to 1996 - a series of 19 years of data. Records were not available for the early years for two of the small hospitals and for NEP, which was not open in the early 1980 s.

\section{Comparison of number of cases in the combined series before and after 1991}

The bottom line of Table 2 is the annual number of acute cases (WE, KP or WKS) at all 17 hospitals. We would not expect chronic cases whose illness started before 1991 to be cured by an increased population supply of thiamin. The lowest incidences for the 19 years 1978-96 were in 1994, 1996, 1993 and 1992. 1995 followed 1980 with the next lowest number of cases. The fluctuation from year to year can be smoothed by looking at 2-yearly incidence of acute cases of WKS (Fig. 1) which shows the trend more clearly. In 1991 only newly milled flour for bread was enriched with thiamin. Existing stocks of unenriched flour had to be used up first, so that the full effect of thiamin fortification would not be expected to show until the next year, 1992.

The mean annual incidence of acute WKS for the years 1978 to 1990 , the 13 years before thiamin enrichment of bread, was 67.7 (SD 14.9). The mean yearly incidence for 1992 to 1996 , the 5 years after thiamin enrichment of bread, was 38.3 (SD 7.0). The difference between these means was statistically significant $(t=3.9, P<0.002)$. 
Table 2 Total incidence of WKS in Sydney hospitals for the years 1978-96 (1991 was the transition year when thiamin enrichment was being introduced to bread

\begin{tabular}{|c|c|c|c|c|c|c|c|c|c|c|c|c|c|c|c|c|c|c|c|c|c|}
\hline & \multirow[b]{2}{*}{78} & \multirow[b]{2}{*}{79} & \multirow[b]{2}{*}{80} & \multirow[b]{2}{*}{81} & \multirow[b]{2}{*}{82} & \multirow[b]{2}{*}{83} & \multirow[b]{2}{*}{84} & \multirow[b]{2}{*}{85} & \multirow[b]{2}{*}{86} & \multirow[b]{2}{*}{87} & \multirow[b]{2}{*}{88} & \multirow[b]{2}{*}{89} & \multirow[b]{2}{*}{90} & \multicolumn{7}{|c|}{ New data } & \multirow[b]{2}{*}{ Total } \\
\hline & & & & & & & & & & & & & & 91 & 92 & $\begin{array}{c}93 \\
(\mathrm{Ma})\end{array}$ & $\begin{array}{c}93 \\
\text { (SR) }\end{array}$ & 94 & 95 & 96 & \\
\hline $\begin{array}{l}\text { BLH } \\
\text { CON } \\
\text { FFH } \\
\text { HOR } \\
\text { LIV } \\
\text { MAN } \\
\text { MVH } \\
\text { NEP } \\
\text { POW } \\
\text { RNS } \\
\text { RPA } \\
\text { RYD } \\
\text { SGH } \\
\text { SVH } \\
\text { SYD } \\
\text { WMH }\end{array}$ & $\begin{array}{r}13 \\
22 \\
0 \\
- \\
6 \\
1 \\
0 \\
- \\
2 \\
0 \\
2 \\
- \\
- \\
10 \\
1 \\
-\end{array}$ & $\begin{array}{c}7 \\
30 \\
0 \\
- \\
8 \\
2 \\
2 \\
- \\
10 \\
4 \\
7 \\
- \\
- \\
30 \\
4 \\
3\end{array}$ & $\begin{array}{r}3 \\
18 \\
0 \\
- \\
4 \\
1 \\
1 \\
- \\
2 \\
1 \\
7 \\
- \\
- \\
6 \\
1 \\
14\end{array}$ & $\begin{array}{r}1 \\
24 \\
0 \\
- \\
1 \\
0 \\
0 \\
- \\
6 \\
7 \\
4 \\
- \\
- \\
15 \\
6 \\
6\end{array}$ & $\begin{array}{r}6 \\
20 \\
0 \\
- \\
1 \\
3 \\
0 \\
- \\
11 \\
3 \\
5 \\
- \\
- \\
18 \\
4 \\
22\end{array}$ & $\begin{array}{r}1 \\
23 \\
0 \\
- \\
0 \\
1 \\
1 \\
- \\
13 \\
4 \\
9 \\
- \\
1 \\
3 \\
0 \\
16\end{array}$ & $\begin{array}{r}0 \\
22 \\
0 \\
1 \\
0 \\
1 \\
1 \\
- \\
6 \\
3 \\
8 \\
- \\
10 \\
5 \\
4 \\
28\end{array}$ & $\begin{array}{r}1 \\
30 \\
1 \\
- \\
4 \\
3 \\
0 \\
- \\
7 \\
7 \\
4 \\
- \\
3 \\
31 \\
3 \\
10\end{array}$ & $\begin{array}{r}0 \\
11 \\
1 \\
- \\
3 \\
6 \\
1 \\
3 \\
4 \\
5 \\
2 \\
- \\
3 \\
11 \\
1 \\
19\end{array}$ & $\begin{array}{r}2 \\
23 \\
0 \\
2 \\
1 \\
0 \\
2 \\
0 \\
7 \\
6 \\
3 \\
- \\
2 \\
14 \\
0 \\
20\end{array}$ & $\begin{array}{r}5 \\
20 \\
0 \\
1 \\
5 \\
1 \\
3 \\
1 \\
14 \\
9 \\
9 \\
2 \\
2 \\
11 \\
2 \\
9\end{array}$ & $\begin{array}{r}3 \\
15 \\
1 \\
1 \\
2 \\
2 \\
0 \\
1 \\
15 \\
7 \\
6 \\
4 \\
2 \\
9 \\
0 \\
18\end{array}$ & $\begin{array}{r}1 \\
18 \\
0 \\
1 \\
0 \\
1 \\
1 \\
2 \\
6 \\
3 \\
4 \\
3 \\
8 \\
9 \\
0 \\
17\end{array}$ & $\begin{array}{r}6 \\
5 \\
1 \\
3 \\
2 \\
2 \\
1 \\
3 \\
9 \\
9 \\
6 \\
3 \\
4 \\
4 \\
4 \\
16\end{array}$ & $\begin{array}{r}3 \\
11 \\
0 \\
3 \\
4 \\
3 \\
4 \\
4 \\
7 \\
2 \\
1 \\
0 \\
6 \\
10 \\
2 \\
4\end{array}$ & $\begin{array}{r}2 \\
14 \\
0 \\
2 \\
3 \\
1 \\
1 \\
2 \\
8 \\
3 \\
5 \\
2 \\
5 \\
7 \\
2 \\
13\end{array}$ & $\begin{array}{r}2 \\
10 \\
0 \\
3 \\
2 \\
0 \\
1 \\
0 \\
5 \\
0 \\
23 \\
1 \\
4 \\
3 \\
2 \\
13\end{array}$ & $\begin{array}{r}4 \\
16 \\
1 \\
0 \\
3 \\
0 \\
2 \\
0 \\
3 \\
1 \\
14 \\
2 \\
4 \\
3 \\
0 \\
7\end{array}$ & $\begin{array}{r}2 \\
21 \\
4 \\
1 \\
5 \\
1 \\
2 \\
3 \\
7 \\
1 \\
13 \\
1 \\
8 \\
4 \\
0 \\
10\end{array}$ & $\begin{array}{r}1 \\
8 \\
4 \\
3 \\
3 \\
7 \\
4 \\
2 \\
4 \\
1 \\
8 \\
1 \\
2 \\
1 \\
0 \\
15\end{array}$ & $\begin{array}{r}61 \\
347 \\
13 \\
19 \\
54 \\
35 \\
26 \\
19 \\
138 \\
73 \\
135 \\
17 \\
59 \\
197 \\
34 \\
247\end{array}$ \\
\hline Total & 57 & 107 & 58 & 70 & 93 & 72 & 89 & 104 & 70 & 82 & 94 & 86 & 74 & 78 & 64 & 70 & 69 & 60 & 83 & 64 & 1474 \\
\hline Total chronic & 2 & 10 & 11 & 6 & 11 & 16 & 15 & 13 & 16 & 14 & 21 & 18 & 23 & 23 & 22 & 34 & 28 & 31 & 34 & 31 & 345 \\
\hline \multirow[t]{2}{*}{ Total acute } & 55 & 97 & 47 & 64 & 82 & 56 & 74 & 91 & 54 & 68 & 73 & 68 & 51 & 55 & 42 & 36 & 41 & 29 & 49 & 33 & 1129 \\
\hline & & & & & & & & & & & & \multicolumn{10}{|c|}{$\begin{array}{c}\text { Mean } \\
|-38.5 \rightarrow|\end{array}$} \\
\hline
\end{tabular}

Ma, Ma \& Truswell (1995) ${ }^{17}$; SR, this study; POW includes results for POW and PHH.

As there may have been a secular decline in the incidence of acute WKS over the longer number of years before thiamin enrichment, the 5 years after 1991 should also be compared with the 5 years before. The mean incidence for 1986-90 was a little lower, 62.8 (SD 8.7) and the incidence for 1992-96 was 38.3 (SD 7.0) as before. The incidence after thiamin enrichment is thus $61 \%$ of the 1986-90 incidence (before thiamin enrichment); the difference between these means is significant $(t=3.73 ; P<0.01)$.

For total cases, acute + chronic WKS, the mean annual incidence for 1978-90 was 81.2 (SD 15.4) and for the years after thiamin enrichment, 1992-96, it was 68.1 (SD 8.0). The mean incidence after 1991 was $85 \%$ of the earlier incidence but this difference was not statistically significant.

\section{Discussion}

In Australia mandatory enrichment of bread with thiamin became effective in 1991. This was a public health measure aimed at reducing deaths from WE and disability from KP. In our earlier retrospective survey of Sydney hospital records the number of acute (i.e. new) cases of WKS appeared to have been lower in 1992 and 1993 but it was always possible that the incidence had randomly fluctuated down further than in previous years.

We are very aware that a retrospective survey of WKS has limitations. Firstly, the clinical diagnosis of WE and
$\mathrm{KP}$ is difficult. Under-reporting must occur; some patients die outside hospital ${ }^{10,12}$ and when hospital patients die the diagnosis of WKS is sometimes first made from neuropathological examination ${ }^{2}$. Secondly, coding with the ICD-9 is not straightforward. The name 'WE' does not appear under 265.1 in volume 1 , the hierarchical classification. The index (volume II) has to be consulted to find that this is the code to use. 'Korsakov's' (sic) psychosis could be allocated to either of two ICD-9 codes. Thirdly, retrospective surveys are also susceptible to the problems of retrieving all

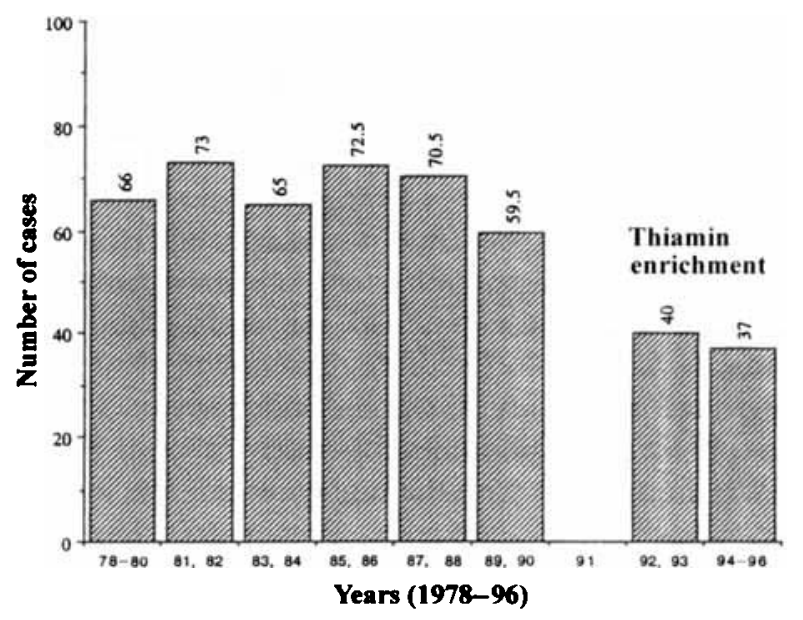

Fig. 1 Annual numbers of acute cases of WE and/or KP in Sydney hospitals as 2 year means around 1991 ( 3 year means at each end). 1991 was the transition year, when thiamin enrichment of bread was being introduced 
requested files in hospital records departments and the inconsistent completeness of clinical notes.

Nevertheless, all these limitations did apply throughout the 19 years that we have searched the hospital records of greater Sydney. The methods used in our two studies were the same. The decision to enrich bread with thiamin was made on the basis of hospital statistics like ours. Prospective studies, with clinicians using standardized criteria ${ }^{23}$ would not be feasible across all hospitals in the area for this uncommon condition because hundreds, if not thousands of hospital medical officers are involved in suspecting and making the diagnosis.

By combining the present survey for 1993-96 with our earlier survey for 1978-93 we can see that there appears to have been a consistent reduction of new, acute cases of WE and/or KP of $39 \%$. The incidence since 1993 has remained about the same; the trend has not fallen further.

Total cases (acute + chronic) have declined by $15 \%$ (not significant) and all of this reduction is due to the change in acute cases. There has been no reduction in the number of chronic cases of KP (who were returning to hospital with other medical problems). Chronic cases as a percentage of total cases ranged from $0 \%$ at RNS to $73 \%$ at CON. The syndrome of $\mathrm{KP}$ is not always a sequel of WE and not always easy to differentiate from other causes of dementia in a problem drinker.

Our finding of a significant reduction of WE and acute KP since 1991 needs to be confirmed by clinical statistics from other centres in Australia and by postmortem studies. In the meantime it suggests that thiamin enrichment of bread has had a beneficial effect on this grave complication of alcoholism. But the other conclusion from our data is that, despite an increase in the population's supply of thiamin, cases of WE and new KP are still occurring in Sydney, almost all in heavy drinkers, and the disease has been less than half prevented.

Our findings are supported by necropsy studies by Harper et al. In recent papers ${ }^{24,25}$ they report a prevalence of WKS in 2212 necropsies in Sydney after 1991 as $1.1 \%$. This is substantially lower than necropsy prevalences of 2.1 in Sydney ${ }^{26}$ in the $1980 \mathrm{~s}$ and 2.8 in Perth (West Australia) in the $1970 \mathrm{~s}^{27}$ found by similar methodology.

At the conference sponsored by the Royal Australasian College of Physicians and the Public Health Association 'it was accepted generally that the effectiveness of thiamin in preventing Wernicke's encephalopathy has not as yet been proved with certainty ${ }^{, 18}$. Addition of thiamin to bread may not reach the target group as efficiently as adding thiamin to Australian beer but it was more politically and technically feasible. Bread enrichment was not a drastic measure and would bring Australia into line with other countries that had for many years been adding thiamin to white bread ${ }^{28}$. Leading psychiatrists ${ }^{29,30}$ and the Royal Australian College of Physicians ${ }^{31}$ considered $^{3}$ that thiamin enrichment of bread would not be sufficient adequately to prevent WKS - addition to alcoholic beverages would have been better and would be needed as well ${ }^{30}$.

Our present and previous ${ }^{12,21}$ data and other Australian studies ${ }^{11.14,32}$ indicate that significantly more patients with WKS had been drinking beer than wines or spirits. The taste of thiamin can merge with the taste of beer ${ }^{14}$, but not that of wine. It is now for the NHMRC, Commonwealth and State health authorities and the brewers to re-examine more seriously the benefits and costs of adding thiamin to Australian beer.

\section{References}

1 Zubaran C, Fernandes JG, Rodnight R. Wernicke-Korsakoff syndrome. Postgrad. Med.J. 1997; 73: 27-31.

2 Harper C. Wernicke's encephalopathy: a more common disease than realised. J. Neurol. Neurosurg. Psychiatry 1979; 42: 226-31.

3 Wood B, Breen KJ. Clinical thiamine deficiency in Australia: the size of the problem and approaches to prevention. Med. J. Aust. 1980; 1: 461-4.

4 Yellowlees PM. Thiamin deficiency and prevention of the Wernicke-Korsakoff syndrome. A major public health problem. Med.J. Aust. 1986; 145: 216-18.

5 Price J. Wernicke-Korsakoff syndrome in Queensland, Australia: antecedents and prevention. Alcobol and Alcoholism 1985; 20: 233-42.

6 Price J, Kerr R. Some observations on the WernickeKorsakoff syndrome in Australia. Br. J. Addiction 1985; 80: 69-76.

7 Victor M, Adams RD, Collins GH. The Wernicke-Korsakoff Syndrome and Related Neurologic Disorders due to Alcobolism and Malnutrition. Philadelphia: FA Davis, second edition, 1989.

8 Bergin PS, Harvey P. Wernicke's encephalopathy and central pontine myelinolysis associated with hyperemesis gravidarium. Br. Med.J. 1992; 305: 517-18.

9 Truswell AS, Konno T, Hansen JDL. Thiamine deficiency in adult hospital patients. S. Afr. Med. J. 1972; 46: 2079-82.

10 Harper $C$. Clinical signs in the Wernicke-Korsakoff complex: a retrospective analysis of 131 cases diagnosed at necropsy. J. Neurol. Neurosurg. Psychiatry 1986; 49: 341-5.

11 Gold J, Perdices M, Lordner $\mathrm{K}$, et al. The WernickeKorsakoff Project. Final Report: January 1986. Canberra: NHMRC, 1986.

12 Truswell AS, Apeagyei F. Alcohol and cerebral thiamin deficiency. In: Jelliffe DB, Jelliffe EFP, eds. Adverse Effects of Foods. New York: Plenum, 1982: 253-8.

13 Anonymous. Wernicke's preventable encephalopathy. Lancet 1979; 1: 1122-3.

14 Price J. Theodoros MT. The supplementation of alcoholic beverages with thiamine - a necessary preventive measure in Queensland? Aust. N.Z. J. Psychiatry 1979; 13: 315-20.

15 Fisher AJ, Yellowlees PM. Prevention of the WernickeKorsakoff syndrome in Australia: a cost-benefit analysis. Med. J. Aust. 1989; 150: 311-17.

16 Anon. Colleges recommend vitamin supplementation of beer. Aust. N.Z. J. Med. 1988; 18: 94.

17 National Health and Medical Research Council (NHMRC). Report of 104th Session, November 1987. Canberra: NHMRC, 1988. 
18 Wodak A, Richmond R, Wilson A. Thiamin enrichment and alcohol. Conference report. Med.J. Austral. 1990; 152: 97-9.

19 National Health and Medical Research Council (NHMRC). Report of 108th Session, November 1989. Canberra: NHMRC, 1990.

20 Mugford DC, Griffiths PJ, Walker AR. Nutrient levels in white, mixed grain and wholemeal bread. An Australia-wide survey of breads from different bakeries and different states. Food Australia 1996; 48: 264-9.

21 Ma JJ, Truswell AS. Wernicke-Korsakoff syndrome in Sydney hospitals: before and after thiamine enrichment of flour. Med. J. Aust. 1995; 163: 531-4.

22 World Health Organization. Manual of the International Classification of Diseases, Injuries and Causes of Death, 9th revision, vols 1 and 2. Geneva: WHO, 1977, 1978.

23 Caine D, Halliday GM, Kril JJ, Harper CG. Operational criteria for the classification of chronic alcoholics: identification of Wernicke's encephalopathy. J. Neurol. Neurosurg. Psycbiatry 1997; 62: 51-60.

24 Harper $C$, Sheedy D, Iara $A$, et al. Is thiamin supplementation useful in preventing Wernicke's encephalopathy? Alcobolism Clin. Exp. Res. 1997; 21: 89A(suppl).

25 Harper C, Sheedy D, Lara A, Garrick RN, Hilton J, Raisaner J. Prevalence of Wernicke's encephalopathy in NSW: has thiamine fortification of flour made a difference? Med. $J$ Australia 1998 (in press).

26 Harper C, Gold J, Rodriguez M, Perdices M. The prevalence of the Wernicke-Korsakoff syndrome in Sydney, Australia: a prospective necropsy study. J. Neurol. Neurosurg. Psychiatry 1989; 52: 282-5.

27 Harper C. The incidence of Wernicke's encephalopathy in Australia - a neuropathological study of 131 cases. J. Neurol. Neurosurg. Psychiatry 1983; 46: 593-8.

28 Bauernfeind JC. Nutrification of foods. In Shils ME, Olson JA, Shike $M$, eds. Modern Nutrition in Health and Disease. Philadelphia: Lea \& Febiger, eighth edition, 1994: 1579-92.

29 Yellowlees $\mathbf{P}$, Lennane J. Thiamine in our bread and wine (correspondence). Med. J. Austral. 1991; 154: 222-3.

30 Connelly L, Price J. Preventing the Wernicke-Korsakoff syndrome in Australia: cost-effectiveness of thiamin supplementation alternatives. Aust. N.Z. J. Publ. Health 1996; 20: $181-7$.

31 Chalmers JP. Thiamine in our bread and wine (correspondence). Med. J. Austral. 1991; 154: 222.

32 Wood B, Currie J, Breen K. Wernicke's encephalopathy in a metropolitan hospital. A prospective study of incidence, characteristics and outcome. Med.J. Austral. 1986; 144: 1216. 